\title{
Formation of three-dimensional Parylene C structures via thermoforming
}

\author{
B J Kim ${ }^{1}$, B Chen ${ }^{2}$, M Gupta ${ }^{2}$ and E Meng ${ }^{1,3}$ \\ ${ }^{1}$ Department of Biomedical Engineering, University of Southern California, 1042 Downey Way, \\ DRB-140, Los Angeles, CA 90089-1111, USA \\ ${ }^{2}$ Mork Family Department of Chemical Engineering and Materials Science, University of Southern \\ California, Los Angeles, CA 90089-1211, USA \\ ${ }^{3}$ Ming Hsieh Department of Electrical Engineering, University of Southern California, 3740 McClintock \\ Ave., EEB-100, Los Angeles, CA 90089-2560, USA \\ E-mail: ellis.meng@usc.edu
}

Received 14 January 2014, revised 19 March 2014

Accepted for publication 31 March 2014

Published 25 April 2014

\begin{abstract}
The thermoplastic nature of Parylene $\mathrm{C}$ is leveraged to enable the formation of three-dimensional structures using a thermal forming (thermoforming) technique. Thermoforming involves the heating of Parylene films above its glass transition temperature while they are physically confined in the final desired conformation. Micro and macro scale three-dimensional structures composed of Parylene thin films were developed using the thermoforming process, and the resulting chemical and mechanical changes to the films were characterized. No large changes to the surface and bulk chemistries of the polymer were observed following the thermoforming process conducted in vacuum. Heat treated structures exhibited increased stiffness by a maximum of $37 \%$ depending on the treatment temperature, due to an increase in crystallinity of the Parylene polymer. This study revealed important property changes resulting from the process, namely (1) the development of high strains in thermoformed areas of small radii of curvature $(30-90 \mu \mathrm{m})$ and $(2) \sim 1.5 \%$ bulk material shrinkage in thermoformed multilayered Parylene-Parylene and Parylene-metal-Parylene films. Thermoforming is a simple process whereby three-dimensional structures can be achieved from Parylene C-based thin film structures with tunable mechanical properties as a function of treatment temperature.
\end{abstract}

Keywords: Parylene C, thermoforming, three-dimensional structures, thermoplastic, fabrication

(Some figures may appear in colour only in the online journal)

\section{Introduction}

Traditionally used as a technique to form large threedimensional (3D) structures from planar polymer films in industry-center mass production processes, thermoforming has been recently extended into the micro-realm to produce micro-scale 3D structures from polymer films [1]. This forming process involves the reshaping of thermoplastic polymers, enabled by softening the material after heating above its glass transition temperature while simultaneously confining the material within a mold of the desired configuration. Upon cooling and removal of the mold, the desired shape is retained. Specifically within biomedical applications, thermoforming of different polymers (e.g. polystyrene, polyethylene terephthalate, polylactic acid) has allowed for successful, mass-scale, repeatable production of lab-on-a-chip as well as other in vitro microfluidic systems [2-5].

Parylene C (here-on referred to as Parylene) is a popular material in biomedical microdevices and microsystem applications largely because of its biocompatibility (USP Class VI), chemical inertness, dielectric properties, moisture barrier properties, and low Young's modulus. Unlike other common polymers used in such applications, Parylene is easily 
deposited as conformal thin films via a room temperature chemical vapor process. Initially used as an encapsulation coating to protect implantable devices [6-8], Parylene is now a commonly used structural material in surface micromachining that can be selectively shaped using standard lithographic processes in combination with oxygen plasma-based removal [9]. More recently, the ability to form 3D Parylene structures have also contributed to the development of novel sensors [10, 11], microfluidics [12-14], and implantable devices $[15,16]$.

Conventional methods to produce 3D Parylene structures utilize two main strategies: (1) the use of temporary sacrificial structures such as photoresist [17, 18] or wax [19] to shape Parylene, or (2) Parylene deposition on molds with topological positive/negative features [20] that then require film release. These well-established processes, though effective, are characterized by complex process steps. Sacrificial structures require extra steps to ensure their complete removal, and removal of films from molds without film or other structural damage can be difficult. Also, these techniques may not be suitable to achieve structures with large aspect ratios, as the Parylene structure is limited by the photolithographic or mold fabrication processes employed. To address these limitations, some studies have focused on leveraging the thermoplastic nature of Parylene to form 3D structures using a hot embossing process [21], as well as a modified polymer bonding technique [22], for both die level $[13,23]$ and wafer level bonding $[22,24]$ to assemble Parylene structures via bonding of a top open structure and a bottom substrate layer. These processes successfully produced microchannel structures while eliminating the need for a sacrificial material.

In this study, we present an alternative method to form 3D Parylene structures adapted from previous work in the thermal shaping of Parylene thin films [25-27]. This strategy utilizes the thermoplastic property of Parylene to thermoform thin film Parylene into 3D structures in a similar manner to previous efforts involving other common polymers previously mentioned. The final desired 3D shape is formed by a simple post-process where a Parylene thin film is placed within a mold, after which it is heated to a temperature between its glass transition temperature $\left(\sim 60-90{ }^{\circ} \mathrm{C}\right)$ and melting point $\left(290^{\circ} \mathrm{C}\right)$ [13], and then slowly cooled below the glass transition temperature. This is achieved without the need for applied bonding pressures. In addition to the formation of a 3D shape, the final device also attains added benefits attributed to the annealing of Parylene layers, such as increased adhesion [28], decreased water permeability and increased dielectric strength [29], and improvement in thermal stability at higher temperatures, namely $>37{ }^{\circ} \mathrm{C}$ for biological applications [30]. Here we present a technique to thermoform Parylene thin films into 3D structures and the characterization of the resulting chemical and mechanical properties of thermoformed Parylene thin films and devices. Thermoforming Parylene allows for a simple process to create desired 3D structures with tunable material properties and expands the potential range of applications of Parylene-based microelectromechanical systems.

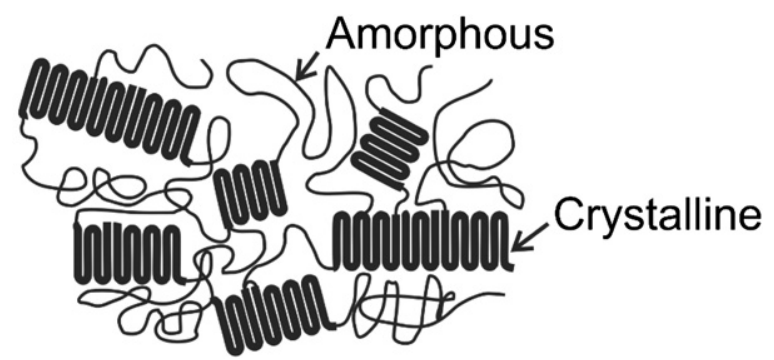

Figure 1. Illustration of semicrystalline, thermoplastic Parylene polymer highlighting crystalline and amorphous regions.

\section{Materials and methods}

\subsection{Thermoforming Parylene}

Parylene free films (single Parylene thin films or ParyleneParylene (PP) dual layers) or devices (Parylene-metalParylene (PMP) sandwiches) were thermoformed by annealing the assemblies (film and mold) in the desired configuration for a set process time (soak time or $t_{\mathrm{S}}$ ) at a certain temperature (soak temperature or $T_{\mathrm{S}}$ ). As a semicrystalline polymer, Parylene chains consist of amorphous and crystalline regions [30] (figure 1). By treating the polymer with soak temperatures between the glass transition point $\left(\sim 90{ }^{\circ} \mathrm{C}\right)$ and the melting point $\left(290{ }^{\circ} \mathrm{C}\right)$, the amorphous regions of the polymer gain energy to rearrange, allowing for softening of the polymer and subsequent molecular relaxation and reorganization of the chains [29, 31]. In thermoforming experiments, the soak temperature was not increased beyond the melting point to avoid device or film complications due to large and potentially damaging changes to the material properties following treatment above that temperature [32].

\subsection{Experimental methods}

A detailed account of PMP device fabrication can be found elsewhere $[15,33]$; the process is briefly summarized here. PMP devices were fabricated by Parylene surface micromachining; all processing was conducted at low temperatures $\left(<90{ }^{\circ} \mathrm{C}\right)$ to avoid bulk material changes associated with high temperature exposure of Parylene. Thin film platinum ( $\mathrm{Pt} ; 2000 \AA)$ was patterned onto a Parylene film (5 $\mu \mathrm{m})$ supported by a silicon wafer. The metal pattern was formed by liftoff using AZ 5214-IR photoresist (AZ Electronic Materials, Branchburg, NJ). A second Parylene film serving as an insulation and structural layer was deposited $(5 \mu \mathrm{m})$ and the final PMP devices were etched out using $\mathrm{O}_{2}$ plasma. A titanium adhesion layer was not used as $\mathrm{Pt}$ has adequate adhesion to Parylene substrates [34], however $\mathrm{O}_{2}$ plasma was used to activate and clean surfaces prior to Pt and Parylene deposition.

Parylene free films or devices were assembled into a specific orientation by using a mold (e.g. microwire, glass rod) to form the desired final shape (figure 2). No additional force was applied to fix the Parylene within the molds, however in some cases aluminum foil or glass slides were placed atop the samples to prevent any film damage associated with exposure to turbulent airflow during the pump and vent 

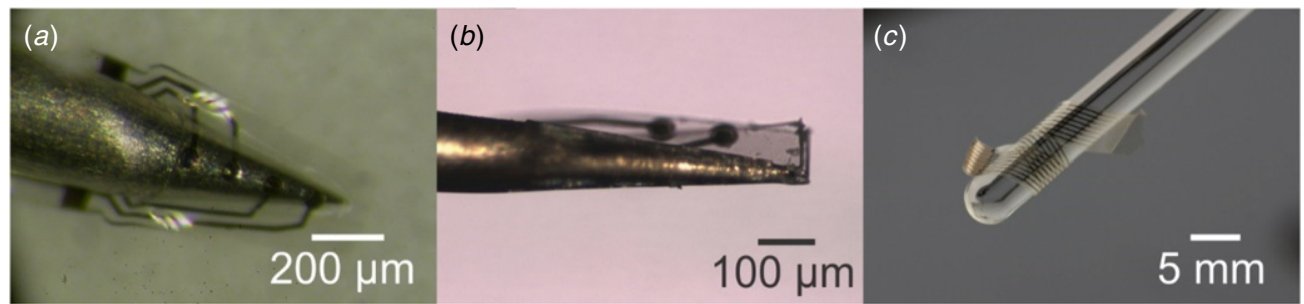

Figure 2. Optical micrographs of molds used to thermoform Parylene 3D structures. $(a)$ Top and $(b)$ side-view of a microwire inserted into a Parylene microchannel to form conical structures. (c) A PMP cable is wrapped around a glass rod to form a macro-coil structure.

steps. These assemblies were then placed within a vacuum oven (TVO-2, Cascade Tek Inc., Longmont, CO) during the subsequent thermoforming process. It is essential to conduct the process in a vacuum environment as Parylene undergoes thermal oxidative degradation at temperatures $>125{ }^{\circ} \mathrm{C}$ in the presence of oxygen [35]. For the purposes of this study, the vacuum environment was maintained at 10 mTorr. In previous studies, nitrogen backflow was also used as an extra precaution to remove any oxygen [36], however in the present study, nitrogen backflow was not present as it was determined that vacuum alone was sufficient in preventing thermal oxidative degradation.

Following placement of the assembled devices into the vacuum oven, the temperature was increased at a rate of $\sim 1.6^{\circ} \mathrm{C} /$ min until the desired soak temperature was achieved, after which the temperature was maintained for a given soak time. Soak times were determined by comparable studies of heat treatment of Parylene films and devices within literature, ranging from $30 \mathrm{~min}$ for $\mathrm{PP}$ bonding [22] to $48 \mathrm{~h}$ for shaping of Parylene $\mathrm{C}$ and improving adhesion between layers [37]. Following a slow overnight $(\sim 15 \mathrm{~h})$ cool down of the samples under vacuum by turning off the heating element, the assemblies were removed from the oven and the molds were easily removed to reveal the final thermoformed shape.

Chemical and mechanical characterization of the effects of the thermoforming process was carried out on Parylene film samples (10 $\mu \mathrm{m}$ thick) that were deposited on $2.54 \times 7.62 \mathrm{~cm}^{2}$ glass slides that were cut into $10 \times 20 \mathrm{~mm}^{2}$ rectangles (for chemical characterization) or $10 \times 10 \mathrm{~mm}^{2}$ squares (for mechanical characterization) using a sharp blade and subsequently released from the glass slides by gentle peeling. The chemical and mechanical changes following variations to the soak temperature and soak time during the thermoforming process were investigated to reveal any material modifications that may have occurred as a result of thermoforming, as well as trends relevant to process tunability. Experiments in which soak temperature variation was evaluated were performed under a constant soak time of $6 \mathrm{~h}$ (soak temperatures: 100, 120, 160, 180, and $200{ }^{\circ} \mathrm{C}$ ), whereas soak time variation experiments were conducted under a constant soak temperature of $200{ }^{\circ} \mathrm{C}$ (soak times: 0.5 , $2,6,12,24$, and $48 \mathrm{~h}$ ). A summary of the testing conditions is given in table 1 .

\subsection{Chemical characterization}

Any changes in the chemical properties of thermoformed Parylene may impact potential functionality of the material
Table 1. Summary of testing conditions for soak temperature and time variation effects on chemical and mechanical properties of Parylene thin films following thermoforming.

\begin{tabular}{ll}
\hline $\begin{array}{l}\text { Soak temperature variation }\left({ }^{\circ} \mathrm{C}\right), \\
t_{\mathrm{S}}=6 \mathrm{~h}\end{array}$ & $\begin{array}{l}\text { Soak time variation }(\mathrm{h}), \\
T_{\mathrm{S}}=200{ }^{\circ} \mathrm{C}\end{array}$ \\
\hline 80 & 0.5 \\
100 & 2 \\
120 & 6 \\
160 & 12 \\
180 & 24 \\
200 & 48 \\
\hline
\end{tabular}

in biological or chemical applications. Properties of untreated Parylene have been thoroughly characterized as an encapsulation material for medical implants [38, 39] or as coating materials for in vitro experiments [40, 41]. For this reason, any possible changes to the bulk and surface chemical properties of the thermoformed films were assessed to observe modifications of the material following the annealing process.

Changes in chemical functionality within the bulk Parylene following thermoforming were assessed using Fourier transform infrared spectroscopy (FTIR; Nicolet iS 10 FT-IR Spectrometer, Thermo Scientific, West Palm Beach, FL), an effective method to identify the presence of certain functional groups within a material based on unique resonance absorption peaks of wavelengths in the infrared. Changes to the surface properties of Parylene films were assessed by measuring contact angles $\left(10 \mu \mathrm{L}\right.$ deionized $\mathrm{H}_{2} \mathrm{O}$ droplet, Model 290-F1, Ramé-Hart Instrument Co., Succasunna, NJ), a method to analyze surface energy using the wetting angle formed by a liquid droplet on a solid surface.

\subsection{Mechanical characterization}

Annealing of Parylene films has been reported to increase the crystallinity of the polymer as the amorphous regions of the polymer gain more ordered structure following thermal treatment [30]; increases in crystallinity were demonstrated to result in increased tensile strength and overall stiffness [42]. In this study, changes to the mechanical functionality of the Parylene films following thermoforming were analyzed by measuring changes to the Young's modulus of thermoformed films using nanoindentation (Berkovich tip, $4 \mu \mathrm{m}$ displacement, MTS Nano Indenter XP, Agilent Technologies Inc., Santa Clara, CA). The changes to the Young's moduli of thermoformed films of varying conditions would alter the stiffness and thus mechanical functionality 

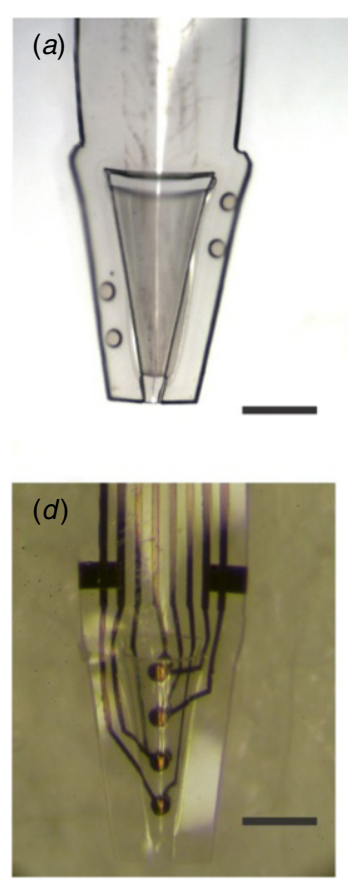

(b)

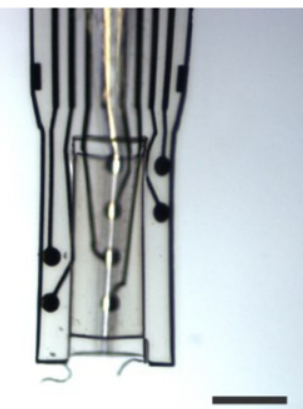

$(e)$

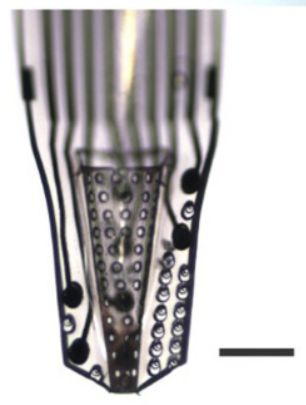

(c)

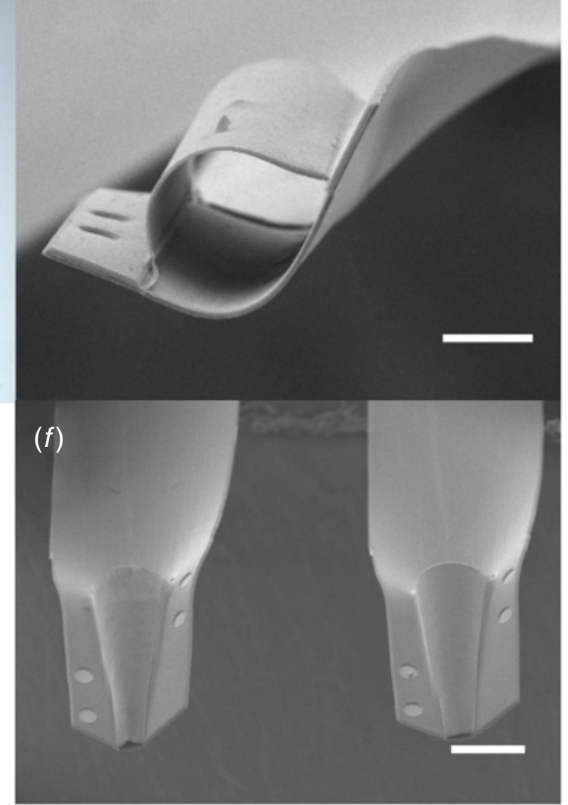

Figure 3. Examples of thermoformed Parylene 3D structures. (a) A thermoformed PP conical structure with a sharp taper. (b) A thermoformed PMP cylindrical structure with electrode sites on the inside and outside of the cylinder. $(c)$ An SEM image of the cylindrical PMP structure. $(d)$ A thermoformed PMP device formed from a Parylene microchannel with electrodes on the top. (e) A thermoformed PMP device formed from a perforated Parylene microchannel. $(f)$ An SEM image of a pair of thermoformed conical devices highlighting the repeatability of the process. (Scale bar $=200 \mu \mathrm{m}$.)

of 3D Parylene structures of differing geometries. Such changes also have implications on the possibility of tuning the mechanical properties of Parylene via annealing processes. The significance of the changes to Young's modulus was determined using a one-way ANOVA test along with a test for linear trend using a statistical software package (Prism, GraphPad Software, Inc., La Jolla, CA).

\section{Results and discussion}

\subsection{Thermoformed structures}

3D Parylene structures that are difficult to fabricate using conventional Parylene structure microfabrication techniques were successfully formed (figure 3 ). The technique used in this study was optimized and utilized in the formation of hollow 3D sheath structures for penetrating neural electrode applications [33], in which sheaths were formed by inserting a tapered microwire mold into opened Parylene microchannels. Conical sheaths of varying tapers ranging from 200 and $300 \mu \mathrm{m}$ base to $70 \mu \mathrm{m}$ tip in diameter and cylindrical sheaths of $300 \mu \mathrm{m}$ in diameter were fabricated using the thermoforming post process. This technique was also successful in forming 3D structures out of a Parylene microchannel with metal electrode sites on top of the structure (figure $3(d)$ ) as well as Parylene microchannels with $15 \mu \mathrm{m}$ perforations (figure $3(e)$ ), exhibiting the robustness of the technique across different initial Parylene structures. Thermoforming was repeatably achieved in sequential processes; two-stage thermoforming was demonstrated in forming 3D micro and macro-structures for device applications. In figure 4 , the hollow sheath cone

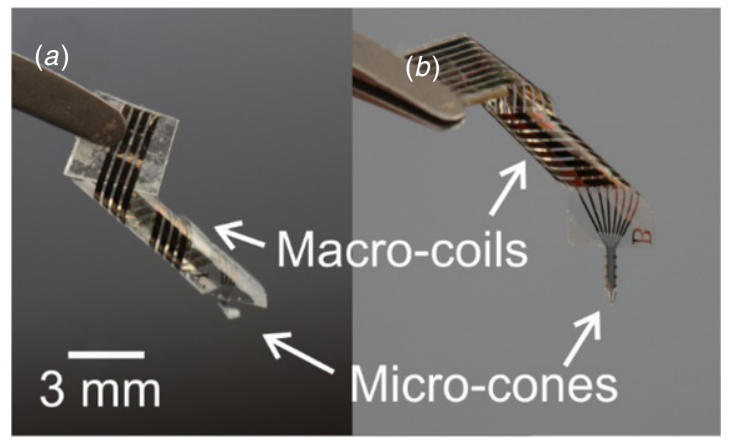

Figure 4. Examples of thermoformed macro-scale coils in (a) 4 channel and (b) 8 channel PMP flexible cables.

structure was first formed in one step, and a secondary macrocoil structure in the incorporated Parylene cable was formed in the second thermoforming step without affecting the initial 3D Parylene microstructure.

Bulk dimensional changes occur as a result of thermoforming and may impact the final desired structure. In thermoformed structures with a small radius of curvature (such as the outer surface of a micro-cone: $r=30-90 \mu \mathrm{m}$ ), high tensile strains can lead to cracking of electrodes following thermoforming if located in the curved region (figure 5). Further investigation indicated that tensile strains did not result from the thermoforming process, but instead were induced during insertion of the microwire mold into the preformed Parylene channel; electrodes that encountered compressive stresses did not exhibit any cracks [43]. It is important that mold-induced mechanical strains do not exceed the ultimate yield strains for the device materials (0.03 for thin film 


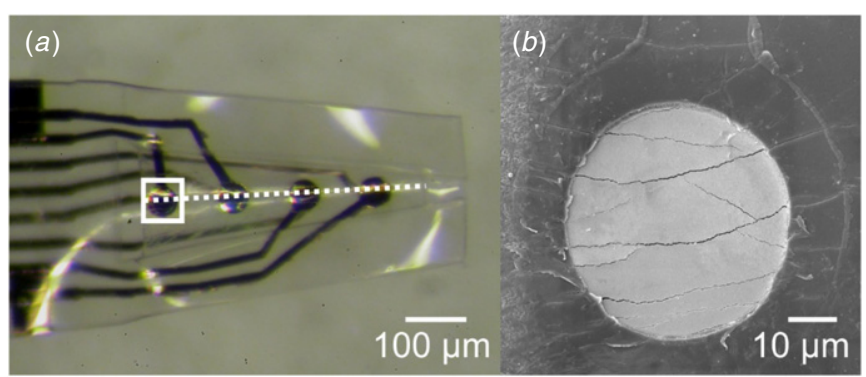

Figure 5. (a) Image of PMP device with a 3D conical structure with electrode sites on the outer face; dashed line indicates the region with high tensile strains leading to cracked electrodes. (b) An SEM image of an electrode (white box) illustrating the formation of cracks along the surface following thermoforming due to high tensile strains.

Table 2. Summary of shrinkage percentages for contact pad and inter-pad regions as well as total cable shrinkages for 8 and 16 channel Parylene FFCs.

\begin{tabular}{|c|c|c|c|}
\hline \multicolumn{2}{|c|}{ Parylene FFC region } & \multirow{2}{*}{$\begin{array}{l}\text { Shrinkage percentage } \\
(\% ; \text { Mean } \pm \text { SD })\end{array}$} & \multirow{2}{*}{$\begin{array}{l}\text { Statistical } \\
\text { significance }\end{array}$} \\
\hline $\begin{array}{l}8 \text { channel } \\
\text { FFC }\end{array}$ & $\begin{array}{l}\text { Contact } \\
\text { pad }\end{array}$ & & \\
\hline & Inter-pad & 2.05 & Yes, \\
\hline & Total pitch & $1.21 \pm 0.30\left(n=10^{\mathrm{a}}\right)$ & Yes, $p=0.0001$ \\
\hline \multirow[t]{3}{*}{$\begin{array}{l}16 \text { channel } \\
\text { FFC }\end{array}$} & $\begin{array}{l}\text { Contact } \\
\text { pad }\end{array}$ & $1.30 \pm 0.35(n=31)$ & Yes, $p<0.0001$ \\
\hline & Inter-pad & 1.40 & Yes, $p<0.0001$ \\
\hline & Total pitch & $1.33 \pm 0.23\left(n=10^{a}\right)$ & Yes, $p<0.0001$ \\
\hline
\end{tabular}

a These $n$ values correspond to five measurements taken between two individual samples.

platinum [44]). In the case of these Parylene micro-cones, the strain limit was reached at a radius of curvature of $\sim 240 \mu \mathrm{m}$, obtained using finite element modeling (data not shown; fabricated cones had radii of 30-90 $\mu \mathrm{m}$ ). It is essential to pre-plan areas of high strains (tensile stresses that are less than the ultimate yield strength of the materials present) based on the final desired geometry following the thermoforming process and avoid placement of thin film metal electrodes in these areas.

Additionally, these bulk dimensional changes can impact applications in which the precise electrode or trace pitch is crucial. As a result of the reorganization of the polymer chains, i.e. the reorientation of the amorphous regions of the polymer into more ordered crystalline portions, a degree of shrinkage exists following the thermoforming process. In the case of Parylene flat flexible cables (FFCs), direct electrical connections to multiple contact pads have been demonstrated using commercially available zero-insertion force (ZIF) connectors [45]. However, these ZIF connectors require precise spacing between metal contact pads for proper insertion and alignment into the connector. Following thermoforming of 8 and 16 channel Parylene FFCs, metal contact pad and inter-pad Parylene spacing shrinkage of $\sim 1.5 \%$ was observed (figure 6 ) and is summarized in table 2 . Statistical significance was measured using a Mann-Whitney nonparametric test in a statistical software package (Prism, GraphPad Software, Inc., La Jolla, CA).

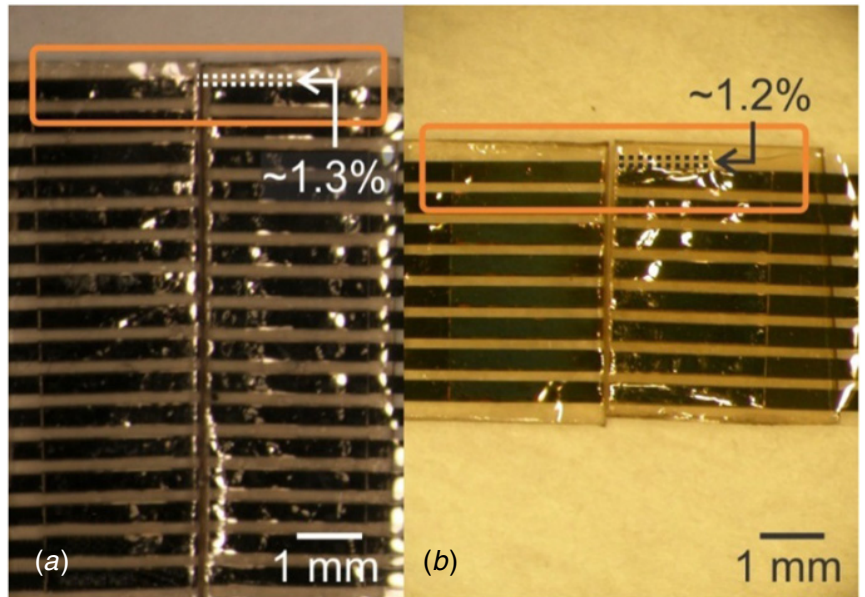

Figure 6. Micrograph images of contact pad regions of $(a) 16$ channel and $(b) 8$ channel PMP cables illustrating bulk shrinkage associated with the thermoforming process.

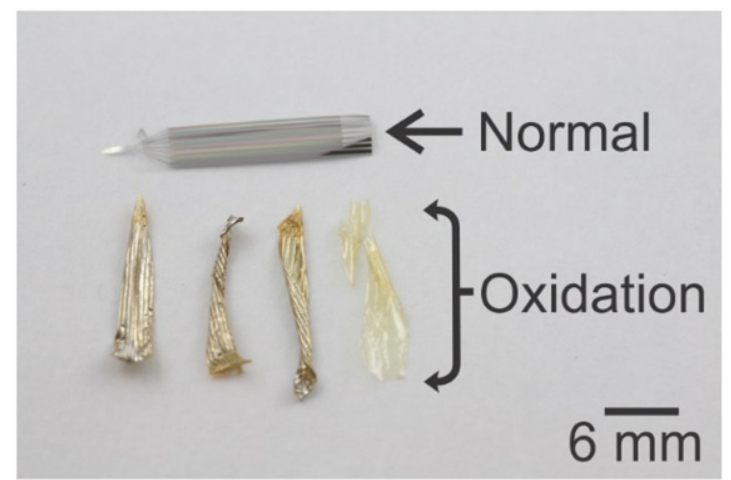

Figure 7. Comparison between a normal PMP cable and those that underwent thermal oxidative degradation due to a leak in the vacuum oven. Note the discoloration of the films as well as brittle failure in the PP sample during handling.

In comparing the shrinkage between contact pad areas (PMP regions) and inter-pad areas (PP regions), it was found that both regions were comparable in shrinkage (no significant difference) for the conditions tested, but larger scale samples may exhibit a different trend as relaxation of built-in intrinsic stress during the deposition of the metal [46, 47] can cause additional bulk material changes alongside shrinkage of the polymer. This shrinkage error propagates in contact pad layouts with larger channel numbers (e.g. 32 channels), which was demonstrated in previous work [36], leading to the prevention of proper pin-pad alignment. In the case of 8 and 16 channels, the dimensional changes were tolerated, however, dimensional changes must be accounted for during the design process for large channel count cables.

The need for a vacuum environment for thermoforming was confirmed as treatment of devices and free films at $200{ }^{\circ} \mathrm{C}$ for $48 \mathrm{~h}$ in an oxygen-rich environment caused by a leak resulted in discoloration (yellowing) attributed to thermal oxidative degradation; samples also exhibited increased brittleness similar to that reported in previous studies [42] (figure 7). The resulting samples were in fact too brittle to endure any standard handling. 
(a)

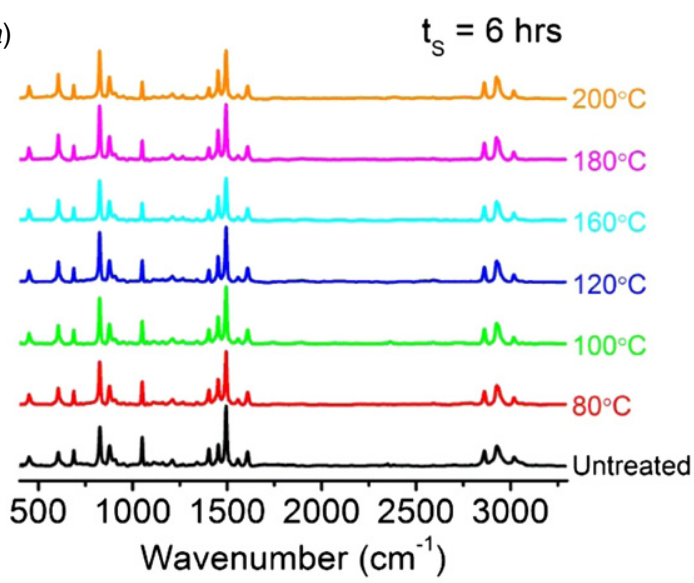

(b)

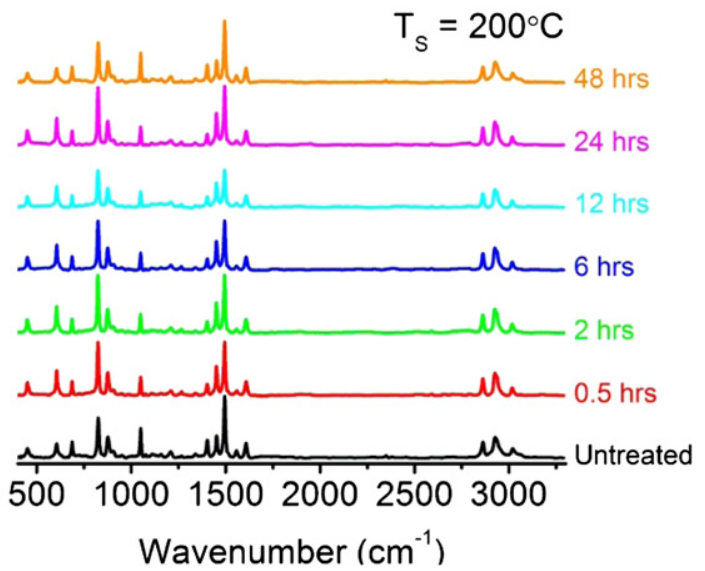

Figure 8. Absorbance measurements from FTIR analysis of thermoformed samples. Varying the $(a)$ soak temperature and $(b)$ soak time had no effect on the chemical composition following the thermoforming process.
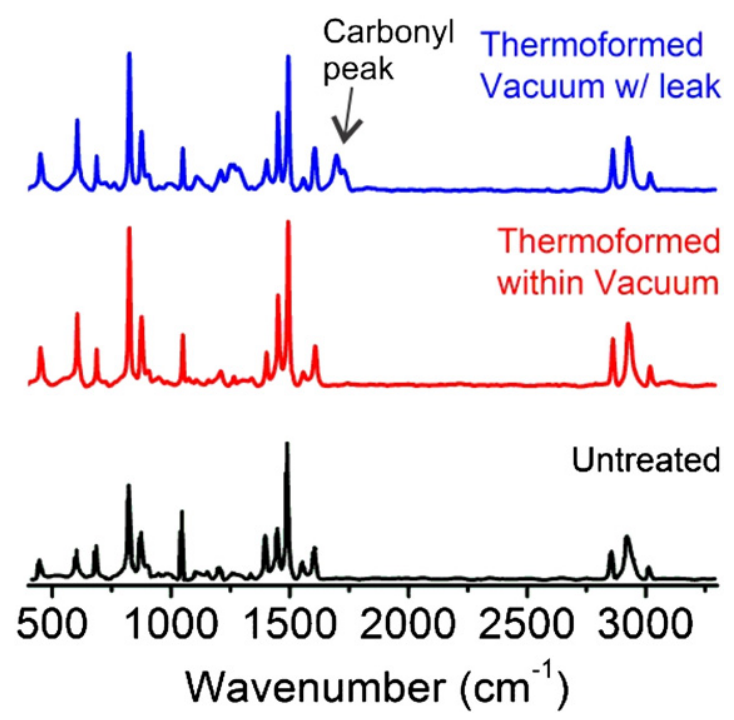

Figure 9. Absorbance results from FTIR measurements of untreated Parylene, Parylene thermoformed under vacuum, and Parylene thermoformed in an oxygen rich environment (leak in vacuum oven). Thermoforming within an oxygen rich environment results in an additional carbonyl peak that is not present in samples thermoformed under vacuum.

\subsection{Chemical and surface characterization}

FTIR analysis on the Parylene samples following thermoforming indicated no new chemical functionalities within the bulk polymer (figure 8). Varying soak temperature and time had no significant effect on FTIR measurements, as the spectra for Parylene was consistent over all thermoformed samples. This analysis was critical in the detection of carbonyl groups that have been observed in Parylene spectra following heat treatment due to thermal oxidation of the polymer [42] (figure 9), which can alter the surface and bulk chemistries. In our samples, the carbonyl addition was prevented by thermoforming Parylene samples in a vacuum environment.

An analysis of the sample surfaces conducted using contact angle measurements indicated no significant changes to the surface energy of Parylene as a function of either soak temperature or time (table 3,4). Samples thermoformed
Table 3. Contact angle measurements obtained from Parylene films following the thermoforming process with varying $T_{\mathrm{s}}\left(t_{\mathrm{s}}=6 \mathrm{~h}\right)$. Results indicated that there was no change in the surface energy with varying soak temperature.

\begin{tabular}{rl}
\hline & Contact angle \\
$T_{s}\left({ }^{\circ} \mathrm{C}\right)$ & $\left({ }^{\circ} ;\right.$ Mean $\left.\pm \mathrm{SD}, n=6\right)$ \\
\hline 0 & $86.7 \pm 0.3$ \\
80 & $87.9 \pm 0.8$ \\
100 & $88.8 \pm 1.5$ \\
120 & $85.2 \pm 1.4$ \\
160 & $89.8 \pm 1.3$ \\
180 & $88.3 \pm 1.0$ \\
200 & $87.9 \pm 1.3$ \\
\hline
\end{tabular}

Table 4. Contact angle measurements obtained from Parylene films following the thermoforming process with varying $t_{\mathrm{s}}\left(T_{\mathrm{s}}=200^{\circ} \mathrm{C}\right)$. Results indicated that there was no change in the surface energy with varying soak time.

\begin{tabular}{ll}
\hline$t_{s}(\mathrm{~h})$ & $\begin{array}{l}\text { Contact angle } \\
\left({ }^{\circ} ; \text { Mean } \pm \mathrm{SD}, n=5\right)\end{array}$ \\
\hline 0 & $86.7 \pm 0.3$ \\
0.5 & $87.1 \pm 2.0$ \\
2 & $88.7 \pm 2.1$ \\
6 & $87.9 \pm 1.3$ \\
12 & $89.7 \pm 1.5$ \\
24 & $89.7 \pm 1.2$ \\
48 & $88.2 \pm 0.3$ \\
\hline
\end{tabular}

under varying soak temperatures and times exhibited contact angles that varied only by a few degrees which demonstrated that thermoforming in a low oxygen environment did not significantly alter the surface energy of Parylene.

\subsection{Mechanical characterization}

Nanoindentation measurements indicated that the Young's moduli of thermoformed Parylene samples increased following the annealing process (table 5, 6), agreeing with changes in crystallinity reported within literature. This increase in crystallinity stems from the development of new crystalline domains within the Parylene's amorphous regions 
Table 5. Young's modulus measurements obtained via nanoindentation of thermoformed films for varying $T_{\mathrm{s}}\left(t_{\mathrm{s}}=6 \mathrm{~h}\right)$. $n$ values correspond to number of points on one large area sample.

\begin{tabular}{cl}
\hline$T_{\mathrm{S}}\left({ }^{\circ} \mathrm{C}\right)$ & $\mathrm{E}(\mathrm{GPa} ;$ Mean $\pm \mathrm{SE})$ \\
\hline Untreated & $2.69 \pm 0.03(n=29)$ \\
80 & $2.90 \pm 0.03(n=31)$ \\
100 & $3.10 \pm 0.03(n=33)$ \\
120 & $3.17 \pm 0.03(n=37)$ \\
160 & $3.57 \pm 0.03(n=25)$ \\
180 & $3.77 \pm 0.02(n=35)$ \\
200 & $3.71 \pm 0.03(n=26)$ \\
\hline
\end{tabular}

Table 6. Young's modulus measurements obtained via nanoindentation of thermoformed films for varying $t_{\mathrm{s}}\left(T_{\mathrm{s}}=200^{\circ} \mathrm{C}\right)$. $n$ values correspond to number of points on one large area sample.

\begin{tabular}{cc}
\hline$t_{\mathrm{S}}(\mathrm{h})$ & $E(\mathrm{GPa} ;$ Mean $\pm \mathrm{SE})$ \\
\hline 0.5 & $3.69 \pm 0.03(n=31)$ \\
2 & $3.76 \pm 0.05(n=12)$ \\
6 & $3.71 \pm 0.03(n=26)$ \\
12 & $3.78 \pm 0.03(n=28)$ \\
24 & $3.78 \pm 0.03(n=23)$ \\
48 & $3.71 \pm 0.03(n=26)$ \\
\hline
\end{tabular}

[30], as well as the formation of a new second crystalline phase [29]. Variation of soak temperature had a larger effect on mechanical stiffness changes (increased 37\%) largely due to the additional energy in the system at greater temperatures leading to increased reorganization and crystalline ordering of the polymer (table 3; one-way ANOVA: $p<0.0001$; test for linear trend: $p<0.0001)$. The smaller change in stiffness as a function of soak time compared to soak temperature (table 4; no significant difference) can be explained by observations in literature in which Parylene crystallinity does not vary greatly following the first couple of minutes of annealing; the kinetics of crystallization (i.e. crystallinity and crystallite size changes) have been shown to be relatively quick [30] and reach a plateau in a matter of minutes [48].

\subsection{Electrochemical effects}

A quick note is mentioned here for completeness regarding effects on the electrochemical properties of thermoformed PMP devices observed in previous studies [49]; exposed PMP electrodes that undergo the thermoforming process were found to increase in electrochemical impedance and have decreased electroactive surface area (data not shown). Although this increase does not affect the functionality of these thermoformed implantable devices [33], the thermoforming process has demonstrated these changes to the sensitive electrode surface that can be explained by a smoothing of the electrode surface during annealing [46] as well as possible mobilized chlorine adsorption on the surface during annealing $[50,51]$ observed in literature. Additional work is underway in ascertaining the source of these changes.

\section{Conclusion}

In this study, we presented a simple method to leverage the thermoplastic property of Parylene to form 3D structures utilizing a thermoforming process. This process was shown to produce both micro and macro-scale 3D Parylene sheath and coil structures for implantable neural device applications, but can easily be extended into a variety of structures for a wide range of applications. Thermoformed samples were characterized chemically and mechanically; heat treatment of Parylene was found to produce no large changes to the surface and bulk chemistries provided that the process is completed within a vacuum environment. Thermoforming was also found to increase the stiffness of Parylene (and thus thermoformed structures) by $37 \%$ (dependent on the process parameters), largely due to an increase in crystallinity following annealing. The soak temperature was found to be more significant in affecting the mechanical properties of the thermoformed structure; the soak times used within this study formed samples with similar mechanical properties regardless of soak time because of the relatively quick kinetics of crystallization. A few consequences to thermoforming were also elucidated: (1) areas of high strain within the mold must be planned and placement of crucial elements within these areas should be avoided, (2) a $\sim 1.5 \%$ shrinkage was observed for the bulk material (no significant difference between PMP and PP shrinkage), and must be considered for size-sensitive devices, and (3) thermoforming must be done within a vacuum environment to prevent oxidative degradation of Parylene resulting in the formation of carbonyl groups within the polymer. Results from this study demonstrate the ease of forming 3D Parylene structures with tunable mechanical properties utilizing the thermoforming process with varying process parameters.

\section{Acknowledgments}

This work was sponsored by the Defense Advanced Research Projects Agency (DARPA) MTO under the auspices of Dr Jack Judy through the Space and Naval Warfare Systems Center, Pacific Grant/Contract no. N66001-11-1-4207 as well as the Viterbi School of Engineering Research Innovation Fund. The authors would also like to thank Dr Jonathan Kuo, Seth Hara, and Curtis Lee for valuable help in the fabrication and testing of pre/post-thermoformed sheathbased neural electrode devices as well as for constructive discussions in optimizing the thermoforming process. We also thank Dr Donghai Zhu of the Keck Photonics Laboratory for additional help with fabrication, Yuzheng Zhang for aid in nanoindentation measurements, and members of the Biomedical Microsystems Laboratory of USC for their assistance.

\section{References}

[1] Truckenmuller R, Giselbrecht S, Rivron N, Gottwald E, Saile V, van der Berg A, Wessling M and van Blitterswijk C 2011 Thermoforming of film-based biomedical microdevices Adv. Mater. 23 1311-29

[2] Dreuth H and Heiden C 1999 Thermoplastic structuring of thin polymer films Sensors Actuators A 78 198-204

[3] Ikeuchi M and Ikuta K 2006 The membrane micro emboss (MeME) process for fabricating 3-D microfluidic device formed from thin polymer membrane Proc. 10th Int. Conf. 
Miniaturized Systems for Chemistry and Life Sciences, Micro Total Analysis Systems, $\mu$ TAS (Tokyo, Japan) pp 693-5

[4] Ikeuchi M and Ikuta K 2008 Membrane micro emboss following excimer laser ablation (MeME-X) process for pressure-driven micro active catheter MEMS'08: IEEE 21st Int. Conf. on Micro Electro Mechanical Systems pp 62-65

[5] Truckenmüller R, Rummler Z, Th S and Schomburg W K 2002 Low-cost thermoforming of micro fluidic analysis chips J. Micromech. Microeng. 12375

[6] Hassler C, Von Metzen R P, Ruther P and Stieglitz T 2010 Characterization of parylene $\mathrm{C}$ as an encapsulation material for implanted neural prostheses J. Biomed. Mater. Res. B 938 266-74

[7] Hsu J M, Rieth L, Normann R A, Tathireddy P and Solzbacher F 2009 Encapsulation of an integrated neural interface device with Parylene C IEEE Trans. Biomed. Eng. $5623-29$

[8] Loeb G E, Bak M J, Salcman M and Schmidt E M 1977 Parylene as a chronically stable, reproducible microelectrode insulator IEEE Trans. Biomed. Eng. BME-24 121-8

[9] Meng E, Li P Y and Tai Y C 2008 Plasma removal of Parylene C J. Micromech. Microeng. 18045004

[10] Giacchino L and Yu-Chong T 2008 Parylene-membrane piezoresistive pressure sensors with $\mathrm{XeF}_{2}$-etched cavity IEEE Sensors pp 1568-71

[11] Gutierrez C A and Meng E 2011 Impedance-based force transduction within fluid-filled Parylene microstructures J. Microelectromech. Syst. 20 1098-108

[12] Li-Yuan C, Po-Ying L, Lingyun Z, Tuan H and Meng E 2008 Integrated flow sensing for focal biochemical stimulation NEMS'08: 3rd IEEE Int. Conf. on Nano/Micro Engineered and Molecular Systems 2008 pp 921-6

[13] Noh H-S, Huang Y and Hesketh P J 2004 Parylene micromolding, a rapid and low-cost fabrication method for parylene microchannel Sensors Actuators B 102 78-85

[14] Ziegler D, Suzuki T and Takeuchi S 2006 Fabrication of flexible neural probes with built-in microfluidic channels by thermal bonding of Parylene J. Microelectromech. Syst. 15 1477-82

[15] Kuo J T W, Kim B J, Hara S A, Lee C D, Gutierrez C A, Hoang T Q and Meng E 2013 Novel flexible Parylene neural probe with 3D sheath structure for enhancing tissue integration Lab Chip 13 554-61

[16] Li W, Rodger D C, Pinto A, Meng E, Weiland J D, Humayun M S and Tai Y C 2011 Parylene-based integrated wireless single-channel neurostimulator Sensors Actuators A 166 193-200

[17] Changlin P, Yu-Chong T, Burdick J W and Andersen R A 2007 Electrolysis-based Parylene balloon actuators for movable neural probes NEMS'07: 2nd IEEE Int. Conf. on Nano/Micro Engineered and Molecular Systems pp 913-6

[18] Walsh K, Norville J and Yu-Chong T 2001 Photoresist as a sacrificial layer by dissolution in acetone $M E M S^{\prime} 01: 14$ th IEEE Int. Conf. on Micro Electro Mechanical Systems pp 114-7

[19] Guo-Hua F and Eun-Sok K 2003 Universal concept for fabricating micron to millimeter sized 3-D parylene structures on rigid and flexible substrates MEMS'03: 16th IEEE Annu. Int. Conf. on Micro Electro Mechanical Systems (Kyoto) pp 594-7

[20] Renxin W, Xianju H, Guangfeng L, Wei W, Fangtian D and Zhihong L 2010 Fabrication and characterization of a Parylene-based three-dimensional microelectrode array for use in retinal prosthesis J. Microelectromech. Syst. 19 367-74

[21] Youn S W, Goto H, Takahashi M, Oyama S, Oshinomi Y, Matsutani K and Maeda R 2007 Fabrication of a micro patterned parylene-C master by hot-embossing and its application to metallic mold replication J. Micromech. Microeng. 17 1402-13

[22] Kim H and Najafi K 2005 Characterization of low-temperature wafer bonding using thin-film parylene J. Microelectromech. Syst. 14 1347-55

[23] Yu-Chang Y, Yu-Tao L, Yen-Chung C and Weileun F 2012 A pneumatic neural probe structure fabricated by parylene thermal bonding technique MEMS'12: IEEE 25th Int. Conf. on Micro Electro Mechanical Systems pp 381-4

[24] Noh H S, Moon K S, Cannon A, Hesketh P J and Wong C P 2004 Wafer bonding using microwave heating of parylene intermediate layers J. Micromech. Microeng. 14625

[25] Gutierrez C A 2011 Development of flexible polymer-based MEMS technologies for integrated mechanical sensing in neuroprosthetic systems $P h D$ Thesis University of Southern California p 219

[26] Huang R and Tai Y-C 2010 Flexible parylene-based 3-D coiled cable NEMS'10: 5th IEEE Int. Conf. on Nano/Micro Engineered and Molecular Systems pp 317-20

[27] Li W, Rodger D C, Weiland J D, Humayun M S and Tai Y C 2005 Integrated flexible ocular coil for power and data transfer in retinal prostheses IEEE-EMBS'05: 27th Annu. Int. Conf. of Engineering in Medicine and Biology Society pp 1028-31

[28] Huang R and Tai Y C 2009 Parylene to silicon adhesion enhancement TRANSDUCERS'09: Int. Solid-State Sensors, Actuators and Microsystems Conf. pp 1027-30

[29] Davis E M, Benetatos N M, Regnault W F, Winey K I and Elabd Y A 2011 The influence of thermal history of structure and water transport in Parylene $C$ coatings Polymer 52 5378-86

[30] Hsu J-M, Rieth L, Kammer S, Orthner M and Solzbacher F 2008 Effect of thermal and deposition processes on surface morphology, crystallinity, and adhesion of Parylene-C Sensors Mater. 20 87-102

[31] Kahouli A, Sylvestre A, Ortega L, Jomni F, Yangui B, Maillard M, Berge B, Robert J C and Legrand J 2009 Structural and dielectric study of parylene $\mathrm{C}$ thin films Appl. Phys. Lett. 94152901

[32] Senkevich J J, Mallikarjunan A, Wiegand C J, Lu T M, Bani-Salameh H N and Lichti R L 2004 Correlation between bond cleavage in parylene $\mathrm{N}$ and the degradation of its dielectric properties Electrochem. Solid State 7 G56-58

[33] Kim B J, Kuo J T W, Hara S A, Lee C D, Yu L, Gutierrez C A, Hoang T Q, Pikov V and Meng E 2013 3D Parylene sheath neural probe for chronic recordings J. Neural Eng. 10045002

[34] Vasenkov A V 2011 Atomistic modeling of parylene-metal interactions for surface micro-structuring $\mathrm{J}$. Mol. Model. 17 3219-28

[35] Nowlin T E, Smith D F Jr and Cieloszyk G S 1980 Thermal oxidative stability of poly-p-xylylenes J. Polym. Sci., Polym. Chem. Edn 18 2103-19

[36] Kim B J, Chen B, Gupta M and Meng E 2013 Three dimensional transformation of Parylene thin film structures via thermoforming MEMS'13: IEEE 26th Int. Conf. on Micro Electro Mechanical Systems pp 339-42

[37] Rodger D C, Fong A J, Li W, Ameri H, Ahuja A K, Gutierrez C, Lavrov I, Zhong H, Menon P R and Meng E 2008 Flexible parylene-based multielectrode array technology for high-density neural stimulation and recording Sensors Actuators B 132 449-60

[38] Sharma A et al 2012 Evaluation of the packaging and encapsulation reliability in fully integrated, fully wireless 100 channel Utah Slant Electrode Array (USEA): implications for long term functionality Sensors Actuators A 188 167-72 
[39] Winslow B D, Christensen M B, Yang W K, Solzbacher F and Tresco P A 2010 A comparison of the tissue response to chronically implanted Parylene-C-coated and uncoated planar silicon microelectrode arrays in rat cortex Biomaterials 31 9163-72

[40] Delivopoulos E and Murray A F 2011 Controlled adhesion and growth of long term glial and neuronal cultures on Parylene-C Plos One 6 e25411

[41] Wei L and Lakhtakia A 2012 Towards bioinspired parylene-C coatings of implant surfaces Bioinspiration, Biomimetics, and Bioreplication (San Diego, CA: SPIE) p 83390R

[42] von Metzen R and Stieglitz T 2013 The effects of annealing on mechanical, chemical, and physical properties and structural stability of Parylene C Biomed. Microdevices 15 727-35

[43] Hara S A, Kim B J, Kuo J T and Meng E 2014 An electrochemical investigation of the impact of microfabrication techniques on polymer-based microelectrode neural interfaces submitted IEEE Trans. Biomed. Eng.

[44] Meirom R A, Alsem D H, Romasco A L, Clark T, Polcawich R G, Pulskamp J S, Dubey M, Ritchie R O and Muhlstein C L 2011 Fatigue-induced grain coarsening in nanocrystalline platinum films Acta Mater. 59 1141-9

[45] Gutierrez C A, Lee C, Kim B and Meng E 2011 Epoxy-less packaging methods for electrical contact to parylene-based flat flexible cables TRANSDUCERS'11: 16th Int. Solid-State Sensors, Actuators and Microsystems Conf. pp 2299-302

[46] Pajkossy T 2005 Impedance spectroscopy at interfaces of metals and aqueous solutions-surface roughness, CPE and related issues Solid State Ion. 176 1997-2003

[47] Grosser M and Schmid U 2010 The impact of annealing temperature and time on the electrical performance of $\mathrm{Ti} / \mathrm{Pt}$ thin films Appl. Surf. Sci. 256 4564-9

[48] Lin J C-H L 2012 MEMS for glaucoma PhD Thesis California Institute of Technology

[49] Kim B J, Hara S A, Chen B, Kuo J T W, Lee C D, Gutierrez C A, Hoang T, Gupta M, Pikov V and Meng E 2013 Evaluation of post-fabrication thermoforming process for intracortical Parylene sheath electrode 6th Int. IEEE EMBS Neural Engineering Conf. pp 379-82

[50] Beshchasna N, Adolphi B, Granovsky S, Braunschweig M, Schneider W, Uhlemann J and Wolter K J 2010 Influence of artificial body fluids and medical sterilization procedures on chemical stability of Parylene C ECTC'10: Proc. 60th Electronic Components and Technology Conf. pp 1846-52

[51] Gruber W, Chakravarty S, Baehtz C, Leitenberger W, Bruns M, Kobler A, Kübel C and Schmidt H 2011 Strain relaxation and vacancy creation in thin platinum films Phys. Rev. Lett. 107265501 